\title{
Espaços de pertencimento: Palmares e Pindjiguiti na poesia afro-brasileira e na guineense
}

\author{
Spaces of belonging: Palmares and Pindjiguiti in \\ Afro-Brazilian and Guinean poetry
}

Moema Parente Augel*

RESUMO: O ARTIGO TRAÇA UM PARALELO DO TRATAMENTO LITERÁRIO DISPENSADO A DOIS ACONTECIMENTOS MARCANTES PARA A HISTÓRIA DO BRASIL E DA GUINÉ-BISSAU, ENQUANTO ESPAÇOS DE PERTENCIMENTO. NA GUINÉ-BISSAU PINDJIGUITI É UM SÍMBOLO NACIONAL; NO BRASIL, PALMARES E SEUS HERÓIS ESTÃO LIGADOS SOBRETUDO ÀS LUTAS E REIVINDICAÇÕES DA POPULAÇÃO AFRODESCENDENTE. ENTRETANTO, O EPISÓDIO E SUAS CONSEQUÊNCIAS NÃO SÃO ASSUMIDOS COMO SÍMBOLOS DE BRASILIDADE, SENDO TEMATIZADOS QUASE EXCLUSIVAMENTE POR INTELECTUAIS, ESCRITORES, MÚSICOS NEGRO-BRASILEIROS.

ABSTRACT: THIS ARTICLE ESTABLISHES A PARALLEL CONCERNING THE LITERARY TREATMENT DEVOTED TO TWO KEY EVENTS IN THE HISTORY OF BRAZIL AND TO GUINEA-BISSAU AS SPACES OF BELONGING. IN GUINEA-BISSAU PINDJIGUITI IS A NATIONAL SYMBOL; IN BRAZIL, PALMARES AND ITS HEROES ARE ABOVE ALL LINKED TO THE STRUGGLES AND CLAIMS OF THE AFRICAN DESCENT POPULATION. THE EPISODE AND ITS CONSEQUENCES ARE NOT ASSUMED AS SYMBOLS OF BRAZILIANNES, BEING THEMATIZED ALMOST EXCLUSIVELY BY AFRO-BRAZILIAN INTELLECTUALS, WRITERS, AND MUSICIANS.

PALAVRAS-CHAVE: PALMARES; PINDJIGUITI; LUTAS LIBERTÁRIAS; LITERATURA GUINEENSE; LITERATURA NEGRO-BRASILEIRA.

KEYWORDS: PALMARES; PINDJIGUITI; LIBERTARIAN STRUGGLES; GUINEAN LITERATURE; AFRO-BRAZILIAN LITERATURE.

* Instituto Nacional de Estudos e Pesquisa da Guiné-Bissau (INEP), Bielefeld, Alemanha. E-mail: moemaparente@uol.com.br. 
Um talho fundo na carne do mapa:

Américas e África margeiam

Um navio negreiro como faca:

mar de sal sangue e lágrimas no meio.

(Oliveira Silveira)

eferências geográficas são parte da comunicação, apontam simbolicamente para um sentido social e guardam uma vigorosa memória histórica e coletiva, contribuindo para um equilíbrio emocional, além de reforçar a "consciência de pertencimento", a que Georg Simmel (1903, p. 41) já se referira. Certos topônimos possuem um conteúdo simbólico que lhes empresta qualidades associadas a uma relação social que tem grande efeito na preservação identitária. Assim é Palmares, assim é Pindjiguiti, palcos, ambos, da revolta contra a opressão e onde o drama gerou a glória da resistência. Continuar a celebrar Palmares, continuar a rememorar Pindjiguiti é antecipar um futuro para a realização do qual muitos se têm empenhado e a literatura é um dos fundamentos dessa arquitetura da esperança.

Um elemento comum aflora tão logo nos ocupamos com o assunto: o amor e apego ao torrão natal, o Tchon guineense, o chão onde se nasceu e onde estão enterrados os antepassados. Os episódios históricos de Pindjiguiti, lá, e de Palmares, aqui, marcam dois espaços e dois momentos que possuem em comum o derramamento do sangue pela liberdade, significando para os guineenses o alvorecer da pátria imaginada e, para os afro-brasileiros, o resgate da dignidade.

Nesse cotejo, uma primeira diferença salta logo à vista: na Guiné-Bissau, o massacre de marinheiros e estivadores no porto do Pindjiguiti nunca foi esquecido, funcionando mesmo como um elemento fundador da nacionalidade guineense, e sua evocação sempre foi recorrente. No Brasil, tanto no discurso ufanista demagogo quanto na elaboração literária, a epopeia do Quilombo dos Palmares permaneceu ausente da historiografia e da consciência nacionais, tendo sido por longo tempo silenciada na sua histórica dimensão. Embora desde os anos setenta historiadores venham, em grande parte, trazendo novas luzes e redimensionando a questão da escravidão em nosso país, Palmares continua fazendo parte quase que exclusivamente da memória do povo negro brasileiro. A revolta e consequente massacre no porto de Pindjiguiti marcaram o início das preparações concretas para a guerrilha que desembocou na indepen- 
dência da Guiné-Bissau, unanimemente considerados símbolo da heroicidade do povo oprimido lutando por sua emancipação. Nenhuma dúvida existe quanto ao fato histórico e o seu significado político, social e emocional para o país, sendo o 3 de agosto, dia do ocorrido, um festejado feriado nacional.

Palmares, igualmente fato histórico e incontestável, ocorrido também durante o período colonial, foi assumido entretanto como propriedade simbólica e emocional apenas pela vastíssima população afro-brasileira. Careceu de ser ampliado por todo o povo brasileiro como metonímia para um marco de rebeldia e conscientização contra a opressão colonizadora - embora seja certo que desde as décadas de 1970 e 1980 se venha verificando uma gradual mudança nos paradigmas que até então norteavam os estudos sobre a escravidão no Brasil. A influência da literatura internacional sobre o escravismo, cada vez maior depois dos anos setenta; os avanços do Movimento Negro e da luta pela democracia no Brasil após o golpe de 1964 contribuíram, entre outros elementos, para novas análises e melhor compreensão da nossa história (cf. CARVALHO, 2000).

João Reis declarou em 2010, numa entrevista à revista digital Terra Magazine, estar a história da escravidão ganhando mais espaço nas escolas; condenava, porém, o tom de "vitimização" que acompanhava, e continua a acompanhar, essa revisão histórica, pois os escravos não foram vítimas passivas de suas circunstâncias, resistiram como puderam ao regime imposto:

[...] os escravos não foram vítimas passivas de suas circunstâncias, [...] resistiram como puderam a virar mera máquina de trabalho, [...] nem sempre através de atos heróicos, da rebeldia aberta, mas através de formas mais sutis de resistência, fazendo corpo mole, fingindo-se doentes, manipulando psicologicamente seus senhores, fugindo para uma festa, batendo atabaques, cultuando seus deuses, aprendendo a ler e escrever a língua do Corão (REIS, J. J., in Terra Magazine).

\section{Pindjiguiti - o fato histórico}

Em 1956, Amílcar Cabral, com outros poucos patriotas da Guiné e de Cabo Verde, criou, em Bissau, o Partido Africano para a Independência da 
Guiné e Cabo Verde (PAIGC), objetivando a conquista da independência para o povo da Guiné e de Cabo Verde, tornando-se, dessa época em diante, núcleo e motor do movimento de independência, espalhando-se por todo o território guineense.

A União Nacional dos Trabalhadores da Guiné, movimento sindical, igualmente clandestino, apoiou os trabalhadores das docas, estivadores e marinheiros na reivindicação salarial que culminou, a 3 de agosto de 1959, com uma greve seguida de manifestações junto ao porto de Pindjiguiti, em Bissau, duramente reprimidas pelas forças coloniais, resultando na morte de cerca de cinquenta trabalhadores e uma centena de feridos.

A partir desse episódio, a luta anticolonial tomou novo impulso. Luís Cabral, primeiro presidente da Guiné-Bissau, documentou em seu livro Crónica da libertação, seu testemunho ocular sobre o episódio de Pindjiguiti:

O massacre de 3 de Agosto, com todo o seu terrível conteúdo de horror e desespero, servira para acordar a consciência de muitos nacionalistas hesitantes. Veio provar a necessidade de lutar por todos os meios para destruir o colonialismo, o que exigia um trabalho longo e duro, pleno de sacrifícios (CABRAL apud CASIMIRO, 2009).

A luta armada prolongou-se por onze anos, até que as forças libertadoras proclamaram unilateralmente a independência da Guiné, em 24 de setembro de 1973, na longínqua e inóspita região montanhosa de Madina de Boé, no Sudeste do país que passou a chamar-se República da Guiné-Bissau.

A pequena e modesta Guiné conseguiu a proeza de afrontar e vencer uma potência europeia, superior em armamento, em conhecimentos bélicos e estratégicos, em possibilidades econômicas e em conexões diplomáticas - elementos que a experiência e a ambição imperialistas tinham aperfeiçoado no decorrer de vários séculos. Um tal feito foi possível graças à força de liderança do engenheiro agrônomo Amílcar Cabral. Essa guerra assimétrica emocionou o mundo e mobilizou uma grande rede de simpatia e solidariedade. O título de "Combatente da liberdade da pátria" é, ainda hoje, decorridos quase quarenta anos, motivo de orgulho e vaidade para os veteranos desse confronto - e não só. Muitos dos que morreram pela independência do Tchon di Guiné têm seus nomes perpetuados em estabelecimentos públicos, como ruas, 
escolas, aeroporto. A guerra de libertação continua a render capital, sendo o tema recorrente para os grupos que detêm as rédeas do país.

Assassinado oito meses antes da proclamação unilateral da independência (a 20 de janeiro de 1973), Cabral tornou-se imortal, kil ku ka ta muri, isto é, aquele que não morre jamais, como outros gloriosos antepassados. Fernando Jorge Teixeira, em artigo virtual, assim se expressa a respeito do herói:

foi juntar-se, nas florestas sagradas, no canto do paraíso, onde estão os nossos antepassados; foi juntar-se aos imortais heróis de Djufunco, aos guerreiros fulas de Alfa Iaia, os guerreiros mandingas de Infali Sonco, aos guerreiros balantas de Nhacra, aos guerreiros manjacos de Caió, aos guerreiros beafadas de Djabada, ao Rei N`Dongo, ao régulo Bopomcolo, ao régulo de Intim, à Rainha Okinka Pampa, ao Honório Barreto, ao Mussa Molo e Unfali Soncó, ao Régulo de Suzana, ao Domingos Ramos e a todos os nossos heróis e mártires de todas as nossas Guerras (TEIXEIRA, 2010).

\section{Palmares - o fato histórico}

A violência inerente ao regime colonial escravista provocou as mais diversas reações de oposição à dominação europeia. Agrupamentos clandestinos de escravos, resultantes de continuadas rebeldias, constituíram uma cadeia ininterrupta de sublevações e resistência à ordem estabelecida pela força do poder senhorial. Do norte ao sul registraram-se diversificadas formas de resistência e de oposição, de inconformismo, de tentativas não só de fuga, mas de reorganização da ordem social surrupiada pelo tráfico negreiro.

Palmares, a maior e mais conhecida comunidade de escravos fugitivos da história das Américas, transformou-se pouco a pouco numa confederação de quilombos, representando esperança para os cativos e ameaça para os senhores, consequência natural ante a violência desumana da ordem escravocrata, desdobrando-se em núcleos de povoamentos interdependentes e articulados.

Situado na Serra da Barriga, no município hoje chamado União dos Palmares, no interior de Alagoas, Palmares tem seus começos antes do findar do século XVI, a partir de um grupo de cerca de 40 escravos que se insurgiram contra os maus tratos em engenhos de cana-de-açúcar onde trabalhavam. Em 
vista dos sucessivos contra-ataques por parte dos fazendeiros, fortificaramse cada vez mais em seus aldeamentos na selva. Ampliando-se sempre mais, Palmares foi se transformando em uma grande e florescente rede de comunidades que, no transcurso do tempo, até o final do século XVII, chegou a uma extensão de cerca de $350 \mathrm{~km}$, albergando, no seu apogeu, cerca de vinte a trinta mil pessoas, repartidas em populosos e florescentes povoados, alguns escondidos nas florestas, em lugares montanhosos.

O Quilombo dos Palmares, depois de existir por mais de um século e ter resistido a mais de quarenta grandes expedições militares, foi finalmente conquistado e destruído pelo poder colonial português. Somente com o auxílio de um forte contingente de tropas vindas de São Paulo e de extraordinário esforço militar, conseguiram os colonizadores desbaratar as povoações e quebrar a inexpugnabilidade daquelas fortificações. Depois da morte de Zumbi, em 1695, grupos palmarinos ainda sobreviveram por alguns anos, tendo sido completamente derrotados por volta de 1700 (FREITAS, 1978, p. 180).

A história dos afro-brasileiros é, desde então, um caminho pleno de resistências e contradições. A auto-colonização, acompanhando a assimilação da ideologia do branqueamento, oscila com a preservação dos valores ancestrais, a altiva afirmação da negritude e a reconstrução da realidade histórica.

Zumbi, o último dos chefes guerreiros, acabou capturado e morto em uma emboscada, quase dois anos depois da derrota e do arrasamento dos principais povoados palmarinos, quando o acesso ao último reduto de resistência foi possibilitado por traição. Aconteceu a 20 de novembro de 1695, quando, atraiçoado por um antigo palmarino, Zumbi sucumbiu no ataque de surpresa.

Graças aos movimentos negros, pelo menos desde a década de oitenta, está sendo resgatada a memória de Palmares e de seus heróis. Conseguiu-se que a Serra da Barriga, cenário de acontecimentos tão importantes, fosse tombada em homenagem a essa relíquia histórica. Palmares é muito mais que um panteão: é o símbolo por excelência da reivindicação e o marco de que resistir vale a pena. É uma construção metonímica, abarcando a ideia de resgate, de glória, de dignidade recuperada. O termo quilombo ampliou-se em sinônimo de resistência e coragem.

Algumas cidades brasileiras decretaram o dia da morte de Zumbi, o 20 de novembro, como Dia Nacional da Consciência Negra, honrando sua memória e seu importante papel para a dignidade de um povo. Com tais celebra- 
ções, chama-se a atenção para a ativa participação do negro brasileiro como sujeito de sua própria história, prescindindo de festejar o 13 de maio.

\title{
A voz da literatura
}

Procurando articulações entre a fala literária guineense e a afro-brasileira, vamos destacar alguns exemplos que merecem atenção.

Semelhante ao "pai da independência", Amílcar Cabral, na Guiné-Bissau, o herói Zumbi, o grande guerreiro e chefe supremo nas últimas décadas de Palmares, é imortal, como afirma Jamu Minka, afro-poeta paulista:

\author{
Zumbi não morreu! \\ ele grita desesperado dentro de mim \\ liberdade! \\ liberdade pro meu povo explorado \\ É um grito-semente \\ de novos tempos (MINKA, 1978, p. 38).
}

Robert Anderson considera terem os afro-brasileiros criado um sistema de referências que apresenta todas as características axiológicas descritas por Mircea Eliade em Myth and Reality, no momento em que a figura de Zumbi adquire um significado abrangente de "uma estrutura de valores tida por uma comunidade" (ANDERSON, 1996, p. 100). O analista americano salienta que o lendário guerreiro está "muito vivo, oferecendo-nos uma rara vista de um mito em processo de fabricação"; e acrescenta que, apesar de dar substância à matéria de Zumbi, as indagações sobre os dados históricos de Palmares são de certa forma irrelevantes ao significado de Zumbi atualmente (Ibidem).

Com efeito, Zumbi está presente na música popular brasileira, nas cantigas de capoeira, nos folguedos populares, no folclore e não podia faltar na literatura afro-brasileira. Selecionando algumas das inúmeras referências a Zumbi (e a Palmares), sobressai a tensão entre o "histórico" e o "mítico" e os textos funcionam como "história sagrada" que toma o herói como "modelo exemplar", reportando-me mais uma vez às palavras de Robert Anderson (Ibidem, p. 105-106). 
Um caminho para a afirmação identitária do afro-brasileiro é justamente a heroicização dos antepassados e a exaltação dos movimentos que se opuseram ao cativeiro: as revoltas armadas e sobretudo os quilombos, buscandose um resgate do papel desempenhado por essas ilhas de resistência. Menos que a conclamação à revolta, é sobretudo o reconhecimento de figuras chaves que fortalece uma auto-imagem positiva e ajuda a manter bem alto o orgulho, dali resultando uma enorme força lírica. Zumbi é visto como expoente ancestral, herói fundador, reencarnado no povo afro-brasileiro que não fica passivo ante as injustiças e a segregação social de que é vítima. O papel representado pelo grande chefe guerreiro é exaltado de forma emocionada e vibrante de orgulho, como exclama o gaúcho Oliveira Silveira em seu poema "Palmares":

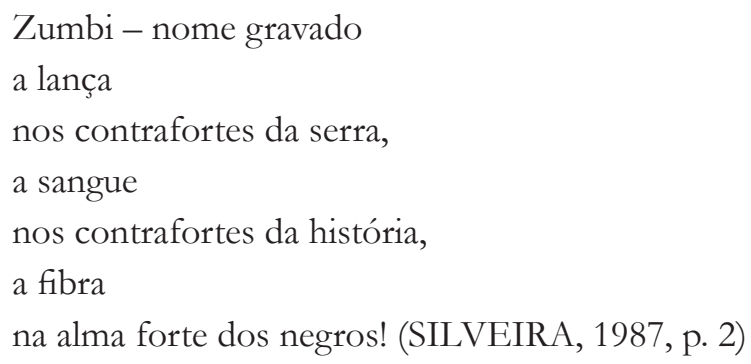

Muitas vezes a auréola sagrada que reveste Zumbi o associa a uma força mística, identificando-o ao espírito ancestral Nzumbi, da cultura kimbundu, o Zâmbi, o criador e senhor onipotente, o deus supremo nos cultos bantu e, no Brasil, também na umbanda. É nome próprio da nobreza iorubá e provavelmente daí deriva o nome, ou título, do principal guerreiro palmarino. São-lhe atribuídos dons excepcionais e divinos: ele é aquele que "arrepia o sol, [...] que engole o sol, [...] que mata o sol", como consta do poema "Candombe", do mineiro Edimilson de Almeida Pereira (PEREIRA, 1991, p. 109).

Domício Proença se refere diretamente a Zambi, a divindade, num dos seus poemas: "Zambi / do Alto / vigia" (PROENÇA, 1984, p. 68). A maiúscula aponta para o sagrado, traduz respeito e devoção. E Abdias do Nascimento, servindo-se de aliterações, não deixa dúvida quanto à ligação entre o divino 
e a personagem histórica: "Zâmbi Zumbi / Zambiampungo / Zumbi zenith" (NASCIMENTO, 1983, p. 31). 'Zumbi aparece, assim, na literatura negra, como agente propiciador da liberdade verdadeira, em oposição à lei perpetrada pela Princesa Isabel.

"Vinculados estreitamente aos mapas da terra natal", escreveu Anthony Smith, "estão os sítios de comemoração que unem gerações de uma comunidade em sua terra natal com os contemporâneos e os que ainda não nasceram" (SMITH, 1998, p. 66). Tal assertiva tanto vale para Palmares, no Brasil, quanto para Pindjiguiti, na Guiné-Bissau. O porto de Pindjiguiti, símbolo maior da resistência guineense contra o colonialismo, é referido em muitos versos, principalmente nas coletâneas poéticas que marcaram o alvorecer da literatura guineense. Encontram-se nos poemas guineenses muitas alusões ao episódio, "No Pindjiguiti / tudo começou, / o genocídio cometido / contra um povo de paz / fez o marco", como se expressa Tony Tcheka no poema "Pindjiguiti" (Mantenhas para quem luta!, 1977, p. 35). São versos da primeira antologia publicada no país recém-libertado, uma saudação aos heróis combatentes.

Os lugares, os sepulcros e os aniversários de morte dos mártires caídos durante as guerras estão impregnados de uma simbologia extremamente significativa para a identidade nacional (SMITH, 1998, p. 67) e o martirológio desempenha um papel fundamental nas cerimônias da nação.

Vasco Cabral (1926-2005), num tom de dramática reportagem, amplia metonimicamente a meia centena de estivadores metralhados na revolta do porto e ressalta assim o sentimento de que os que se sacrificaram pela causa comum são - como se expressou Smith - receptáculos sagrados da nação mesma (Ibidem, p. 69). Eis um trecho do conhecido poema "Pidjiguiti":

3 de agosto

1959.

Bissau desperta inquieta

do sono da véspera.

1. Zambiampungo, o mesmo que Zâmbi, divindade suprema dos cultos de origem bantu e da umbanda, correspondente ao Olorum iorubano e ao Deus cristão (LOPES, 2004, p. 693). 
Sopra um vento de morte

no cais de Pidjiguiti!

E de repente

O clarão dos relâmpagos

O ribombar dos trovões.

$\mathrm{O}$ meu povo morre massacrado

No cais do Pidjiguiti! (CABRAL, 1981, p. 91)

No belo poema "O cantor miserável da noite no cais", datado de março de 1975, Pascoal D’Artagnan Aurigemma (1938-1991) evoca nominalmente, por duas vezes, num só longo verso, os estivadores das mais variadas origens, numa insinuação velada à famosa revolta dos estivadores e à "unidade e luta", um dos slogans do recém-vitorioso movimento libertador:

\section{Estão ali}

no cais

Ansumane Becô, Infamará, Bicinti Cabupar, Malan Seidi, Djodje Badiu, Batipom Cá..

Estão ali uma data de anônimos

da noite no cais! (AURIGEMMA, 1996, p. 55)

De Tony Tcheka, lembramos o poema "Poesia Brava" (TCHEKA, 1996, p. 81-82), que ostenta uma teimosa afirmação, na certeza de que não foram debaldes as "convulsões" das muitas lutas pela liberdade que exigiram renúncias e provações ("Aprendemos no sofrimento / das manhãzinhas de cuntango / sem pão / sem manteiga"; Ibidem), mas o sacrifício dos estivadores mortos produziu frutos. O texto, de 1978, mostra-se impregnado pelo orgulho de finalmente não depender nem de "compromissos" nem de "discursatas":

Cremos no hoje

caldeado nas convulsões de Pindjiguiti

no amanhã sonho-flor 
sem recuos compromissos

ou discursatas

capeadas pelo suave odor da luta (Ibidem, p. 82).

Onze anos mais tarde, Tony Tcheka externa, em "Ode a Pindjiguiti", outros sentimentos. O tropo simbolizando a luta pelo ideal é reunido à imagem materna (recorrente na poesia e na música guineenses), sugerindo com amargura que o sacrifício dos que tombaram não produziu os frutos esperados, as mães não puderam parir a verdadeira libertação:

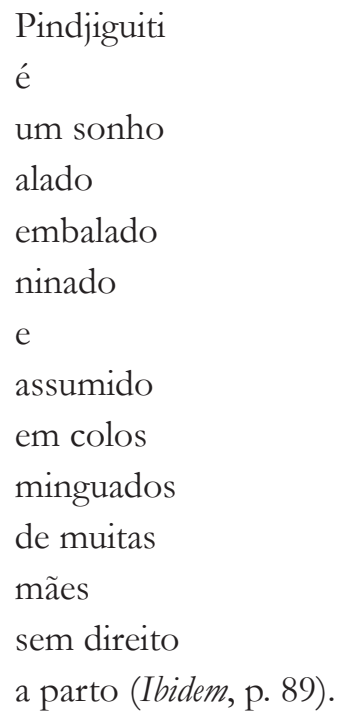

Tony Tcheka, igualmente em "Perdão ao poeta", expressa sua desilusão face ao fracasso dos ideais revolucionários, dirigindo-se retoricamente a José Carlos Schwarz, poeta e compositor famoso pelas suas decididas intervenções críticas, indo buscar de novo aquele episódio, histórico, sim, mas também fabulado, que persiste como referência ao mesmo tempo grata e melancólica:
Acolá
jaz a esperança
do hino adiado
da palavra amansada
de vozes emudecidas 


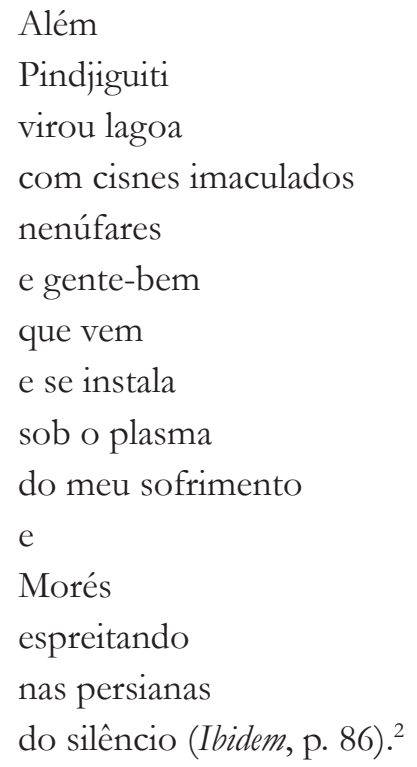

A unidade nacional é forjada a partir de uma memória ou de histórias imaginadas e, ao mesmo tempo, de muitas omissões. Apagam-se acontecimentos ligados à violência das guerras expansionistas, à arbitrariedade ou à arrogância dos vencedores e ao artificialismo do traçado das fronteiras, dando lugar ao esquecimento das condições de produção dessa unidade. Agnelo Regalla, em "Quinhentos anos de história”, denuncia a perda de suas raízes, a condenação ao esquecimento e a daí resultante a-historicidade, corolário da falta de liberdade que impossibilita o colonizado a conhecer as origens e a determinar ele mesmo seu destino:

"Quinhentos anos de história

(Sem história...)

Quinhentos anos de escravidão e exploração

Quinhentos anos sem luz", diz o poeta (REGALLA, 1990, p. 117).

Jorge Cabral (1952-1994), sobrinho de Amílcar Cabral, é autor de um longo poema intitulado "Um sonho - uma realidade" (CABRAL, 1998, p. 23-

2. Morés é símbolo de resistência, porque ali se travou, durante as lutas da independência, uma das batalhas decisivas a favor dos insurgentes. 
33), que merece atenção. A expressão crioula Cabral ka muri!, presente no cotidiano guineense, está implícita no desenrolar das cenas que constituem uma verdadeira trama épico-dramática desse poema de centenas de versos e dezenas de estrofes. Em enunciados na primeira pessoa, o eu poético, projetando-se no drama, relembra a cena do assassinato do grande líder, mesclando-a com elementos de sua imaginação poética, encenando estar diante da personalidade auratizada que com ele dialoga:
um sorriso tranquilo
E sereno
Iluminava o seu rosto
Um rosto radiante
De luz, de vitória (Ibidem, p. 24).

No poema, a vítima ali referida não é o líder Amílcar, e sim seus agressores e assassinos, classificados como "criminosos", "infames", enquanto que tudo relativo ao herói é "radiante", "irreal", "insondável”, "apaziguante”, "luminoso", "divino", multiplicando-se os sintagmas que indiciam o clima de exaltada heroicização. O poema é longo, mas segue no mesmo tom:

Ele pôs-se então

A falar-me

E vi os seus olhos...

A sua luz

Fazia da noite

Um dia luminoso [...]

O seu rosto

Irradiava de glória

E o seu sorriso

De uma majestade

quase divina (Ibidem, p. 27).

Os assassinos julgavam ser o herói "apenas de carne feito", mas, sacralizado pela veneração dos guineenses, Cabral continua presente, 
$[\ldots]$ aqui,

Como sempre

E para sempre [...]

vivo

Nos corações e nos atos

De todos os filhos dignos

Do nosso povo imortal

Da nossa terra africana (Ibidem, p. 30).

\section{Conclusão}

O processo de silenciamento que envolveu o episódio emblemático de Palmares, veiculado pela historiografia, pelas instituições escolares e por quase todas as instâncias da construção da consciência coletiva da nação brasileira, confirma o descaso a que o afro-brasileiro era relegado, desconsiderado como sujeito significante, indigno de encarnar a heroicidade da nação.

Apesar de todos os reais avanços verificados no tratamento da causa negrobrasileira, a luta contra as atrocidades da escravidão não foi considerada um aspecto oportuno nem aplicável para a construção de uma imagem positiva, na visão da nação, para as camadas dirigentes nem para as elites brasileiras. No discurso da formação histórica brasileira, foi perdida a oportunidade de Palmares, como força histórica e heroica, ser sublimado como forma de identificação nacional, tendo sido muitas vezes, visto mesmo com precaução, radicalizado como um estopim reivindicatório para movimentos de identificação e de auto-afirmação negros. Como Décio Freitas concluiu: "Na historiografia dos dominadores, Palmares perpassa como um episódio marginal escassamente significativo; na dos dominados, brilha como um dos seus momentos de maior grandeza (FREITAS, 1978, p. 189).

A redução de Palmares a um signo afro-brasileiro, restringindo assim seu prestígio e amplitude, evidencia a violência simbólica exercida pela intelectualidade hegemônica e elitista de nosso país, ao impor sua autoridade e sua ideologia, elaborando e assegurando sua reprodução social através da ação dos agentes políticos e das instituições na formação da consciência coletiva, preservando as funções sociais eleitas como exemplares. 
Vimos que Pindjiguiti, por outro lado, é celebrado na Guiné-Bissau como precioso capital simbólico, pleno de carisma. O que foi um momento de protesto espontâneo contra uma injustiça assumiu uma marca de distinção, impalpável, mas onipresente, na consciência coletiva, e seu significado continua a ser reforçado por signos distintivos que reafirmam seu prestígio. $\mathrm{O}$ reconhecimento de sua efetividade simbólica, convertido em um bem cultural nacional, foi e continua a funcionar até mesmo enquanto instrumento político, sempre presente.

Assim, enquanto na literatura guineense e na música as vozes que se erguem evocando Pindjiguiti são vozes guineenses sem restrição, na música e na literatura brasileira, são quase exclusivamente vozes negras que celebram Palmares e não o deixam ser silenciado enquanto capital cultural brasileiro.

Mesmo com grandes lacunas na incorporação de Palmares no ideário dos conceitos nacionais, não pode haver nenhuma dúvida que as lutas libertárias representam afirmações de brasilianidade e não implicam nenhuma conotação de distanciamento ou de separatismo. Nem a fidelidade aos orixás e o culto aos ancestrais, nem a evasão para o território místico dos antepassados ou para o regaço acolhedor da Mãe África, nem o recurso ao efeito consolador da sublimação dos sentimentos, dos sonhos e anelos, nem tampouco a atitude concreta de solidariedade para com os oprimidos da África e de todo o mundo constituem os únicos meios possíveis para o afro-brasileiro na busca ou no fortalecimento da sua auto-identificação. Muito pelo contrário, o escritor negro brasileiro de hoje em dia, armado com o instrumento do seu verbo, tem em vista o esforço comum de emancipação social, econômica e também psicológica da população negra no Brasil. Ela é parte e instrumento de um processo de conscientização e de resgate não só cultural, mas sobretudo moral que, embora tendo suas raízes emocionais e históricas no passado africano, é visceralmente brasileiro.

\section{Referências bibliográficas}

ANDERSON, Robert. O mito de Zumbi: implicações culturais para o Brasil e para a diáspora africana. In: Afro-Ásica. Revista do Centro de Estudos Afro-Orientais da Universidade Federal da Bahia, n. 17, 1996, p. 99-119.

AUGEL, Moema Parente. $O$ desafio do escombro. Nação, identidades e pós-colonialismo na literatura da Guiné-Bissau. Rio de Janeiro: Garamond, 2007. 
AURIGEMMA, Pascoal D'Artagnan. Djarama e outros poemas. Bissau: Instituto Nacional de Estudos e Pesquisa (INEP), 1996.

BOURDIEU, Pierre. O poder simbólico. Lisboa; Rio de Janeiro: DIFEL; Bertrand, 1989.

CABRAL, Rui Jorge Dias. Os marinheiros da solidão. Bissau: Instituto Nacional de Estudos e Pesquisa (INEP), 1998.

CABRAL, Luís apud CASIMIRO, Fernando. Pindjiguiti: memórias de uma realidade presente, 08 ago. 2009. Disponível em: <http://www.didinho.org/PINDJIGUITIMEMORIASDEUMAREALIDADEPRESENTE.htm>. Acesso em: 18 jun. 2012.

CABRAL, Vasco. A luta é a minha primavera. Oeiras: África, 1981.

CARVALHO, Marcus J. M. de. Resistência escrava no Brasil: raízes e roteiros de algumas discussões recentes. Disponível em: < http://bibliotecavirtual.clacso.org.ar/ar/ libros/aladaa/carval.rtf>. Acesso em: 19 nov. 2010.

FREITAS, Décio. Palmares. A guerra dos escravos. 2. ed. Porto Alegre: Movimento, 1978. LOPES, Nei. Enciclopédia brasileira da Diáspora africana. São Paulo: Selo Negro: 2004.

Mantenhas para quem luta! A nova poesia da Guiné-Bissau. Bissau: Conselho Nacional de Cultura, 1977. Reprint Bissau: União Nacional de Artistas e Escritores, 1993.

MINKA, Jamu. Zumbi. In: Cadernos Negros 1. São Paulo: Quilombhoje, 1978, p. 38.

NASCIMENTO, Abdias do. Axés do sangue e da esperança (orikis). Rio de Janeiro: Achiamé, 1983.

PEREIRA, Edimilson de Almeida. Corpo vivido. Belo Horizonte: Mazza; D’ Lira, 1991.

PROENÇA Filho, Domício. Dionísio esfacelado. Quilombo dos Palmares. Rio de Janeiro: Editora Achiamé, 1984.

REGALLA, Agnelo. “Quinhentos anos de história”. In: Antologia poética da Guiné-Bissau, Lisboa: Editorial Inquérito, 1990, p. 117.

REIS, João José. Entrevista. Terra Magażine. Disponível em: < http:/ / terramagazine.terra.com.br/interna/0,,OI4824149-EI6595,00-Reis+Escravos+nao+foram + vitim as+passivas.html>. Acesso em: 14 fev. 2011.

SIMMEL, Georg. "Soziologie des Raumes". In: Jahrbuch für Gesetzgebung, Verwaltung und Volkswirtschaft im Deutschen Reich. Ano 27, 1903, p. 27-71.

SILVEIRA, Oliveira. Poema sobre Palmares. Porto Alegre: Edição do Autor, 1987. . Poemas. Antologia. Porto Alegre: Edição dos Vinte, 2009.

SMITH, Anthony D. Conmemorando a los muertos, inspirando a los vivos. Mapas, recuerdos y moralejas en la recreación de las identidades nacionales. In: Revista Mexicana de Sociología. México, 60 (1), p. 61-80, 1998.

TCHEKA, Tony. Noites de insónia na terra adormecida. Bissau: Instituto Nacional de Estudos e Pesquisa (INEP), 1996.

Recebido em 19 de junho e aprovado em 14 de outubro de 2012. 